\title{
A presentation of aids-related ophthalmic disease in a severely immunocompromised patient
}

\author{
BY SALLY CHETRIT, OD
}

\section{Introduction}

$\mathrm{T}$ he human immunodeficiency virus (HIV) is a retrovirus causing progressive damage to the immune system by selectively attacking and destroying a specific type of white blood cell, the CD4 Tlymphocyte. The acquired immunodeficiency syndrome (AIDS) is known to be the final stage of the HIV infection. ${ }^{1}$ A patient is classified as having AIDS when their CD4 T-lymphocyte count drops below 200 cells per microlitre, or their CD4 T-lymphocyte percentage of total lymphocytes is less than $14 \%{ }^{2}$ Prominent risk factors for contracting HIV include injection drug abuse and high risk sexual contact. ${ }^{3}$ As of December 2008, the Centers for Disease Control and Prevention estimates that there are 1.1 million people living with HIV in the United States. This number is expected to grow as antiretroviral therapy prolongs the lives of patients infected with HIV and inevitably increases the opportunity for transmission to others. ${ }^{4}$ In the last quarter century there has been a shift in demographics of the AIDS epidemic: $25 \%$ of HIV infections being diagnosed among women and the virus disproportionately affecting racial and ethnic minorities. Over half of the new diagnoses are among African Americans.,

HIV retinopathy is the most common ocular manifestation of AIDS, affecting between $40 \%$ and $60 \%$ of HIV-positive patients with CD4 T-lymphocyte count below 100 cells per microlitre. ${ }^{7}$ Clinically, this retinal microvasculopathy presents with cotton-wool spots and microaneurysms in the posterior pole. The presence of HIV retinopathy is an important marker for patients with significantly compromised immune status who are at risk for developing more severe and vision-threatening ocular opportunistic infections. ${ }^{7}$

Cytomegalovirus retinitis (CMVR) is the most common ocular opportunistic infection associated with AIDS, affecting approximately 9\% of AIDS patients. ${ }^{7}$ There are two clinical forms of CMVR. The fulminant form presents with confluent retinal necrosis and hemorrhaging in the posterior pole region. The indolent form of CMVR presents as granular lesions in the peripheral retina, accompanied by little to no hemorrhaging. Treatment typically includes a course of

\section{ABSTRACT}

Background: Human immunodeficiency virus (HIV) retinopathy is the most common ocular manifestation of the acquired immunodeficiency syndrome (AIDS), serving as an important marker for patients with significantly compromised immune status who are at risk for developing severe and visionthreatening ocular opportunistic infections. This case report describes a presentation of HIV retinopathy and cytomegalovirus (CMV) retinitis, and reviews the current management options.

Case Report: A 40-year-old black male presented for a comprehensive eye exam to rule out HIV-related ophthalmic disease. At his initial visit, a dilated fundus examination revealed HIV retinopathy of the left eye. Upon subsequent examinations and as his immune status diminished, the patient developed CMV retinitis of the right eye. The patient was treated successfully with a course of highly active antiretroviral therapy (HAART) and oral valgancyclovir.

Conclusion: CMV retinitis is the most common ocular opportunistic infection associated with AIDS. Treatment with systemic HAART and concomitant anti-CMV therapy leads to reconstitution of the immune system and regression of the retinitis.

Keywords: Human immunodeficiency virus (HIV); Acquired immunodeficiency syndrome (AIDS); HIV retinopathy; Cytomegalovirus retinitis; Gancyclovir; Highly active antiretroviral therapy (HAART). 
highly active anti-retroviral therapy (HAART), with concomitant administration of anti-CMV specific agents. ${ }^{7}$

The following is the case of a severely immunocompromised HIV positive patient who developed HIV retinopathy and subsequent CMVR.

\section{Case Report}

A 40-year-old HIV-positive black male inpatient was referred to the Eye Clinic at the Woodhull Medical and Mental Health Center (Brooklyn, New York) for a comprehensive eye examination to rule out HIV-associated ophthalmic disease.

The patient was diagnosed with HIV in July 2008. He was lost to follow-up until twelve weeks later, when he was admitted to the hospital with signs and symptoms of acute esophagitis. It was at this time that the patient was referred to the Eye Clinic for his first evaluation. He presented without any ocular symptoms and a review of systems revealed only a positive HIV status with concomitant esophagitis.

At the time of his admission, the patient presented with an elevated erythrocyte sedimentation rate, of $82 \mathrm{~mm} / \mathrm{hr}$ (reference $0-15 \mathrm{~mm} / \mathrm{hr}$ ), positive Cytomegalovirus immunoglobulin $\mathrm{G}$ titers, positive HIV antibody screening test (Western Blot), elevated quantity of CMV DNA, with 2,733 copies/mL

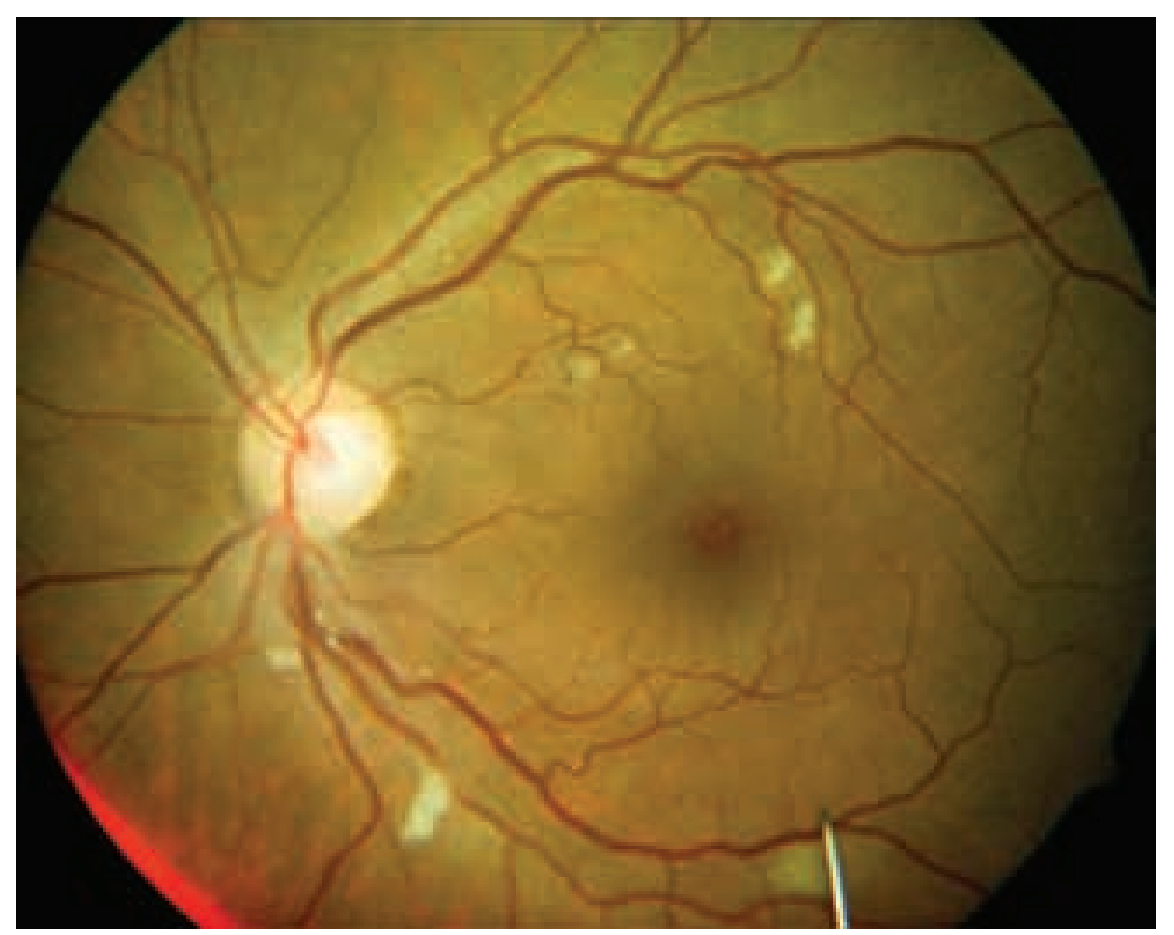

Figure 1: Multiple cotton-wool spots at the posterior pole, left eye - initial visit.

(reference $<200$ copies $/ \mathrm{mL}$ ), and a CD4 T-lymphocyte count of 7 cells $/ \mu \mathrm{L}$ (reference 544-1894 cells $/ \mu \mathrm{L})$.

The patient had been initiated on HAART, and reported a compliance rate of greater than $95 \%$. The patient's therapy consisted of the following agents: Kaletra ${ }^{\circledR}$ (Abbott Laboratories, North Chicago, Illinois), which is a co-formulation of two protease inhibitors - lopinavir and ritonavir, and Truvada ${ }^{\circledR}$ (Gilead Sciences Inc, Foster City, California), which is a combination of two nucleoside reverse transcriptase inhibitors - emtricitabine and tenofovir. Both medications were administered orally, twice daily.

\section{Initial ocular examination} revealed multiple cotton-wool spots in the posterior pole of the left eye, without signs of hemorrhage, or exudation (Figure 1). The right eye appeared to be clear of microvascular anomalies (Figure 2). Visual acuities were measured to be 20/20-, right eye and left eye. The patient was diagnosed with HIV retinopathy of left eye. No additional treatment was indicated, however, because of the patient's significantly low CD4 count, he was instructed to continue with current HAART regiment and to return to the Eye Clinic in one month for follow-up. Other than the cotton-wool spots detected

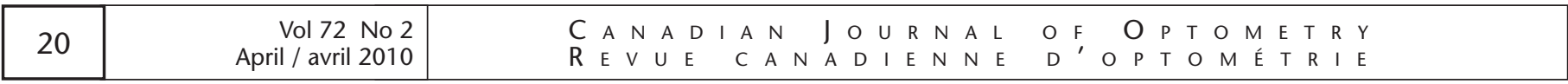




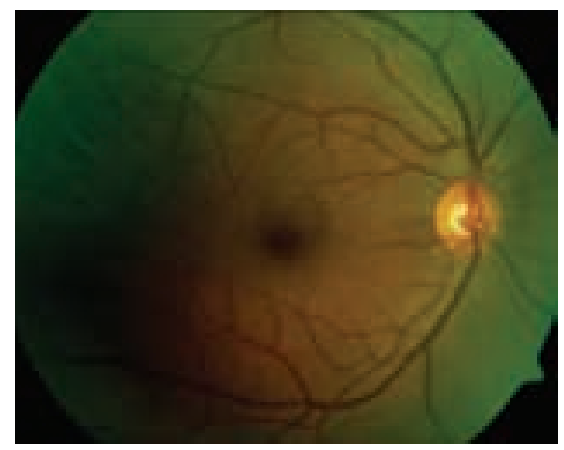

Figure 2: Posterior pole without signs of retinopathy, right eye - initial visit.

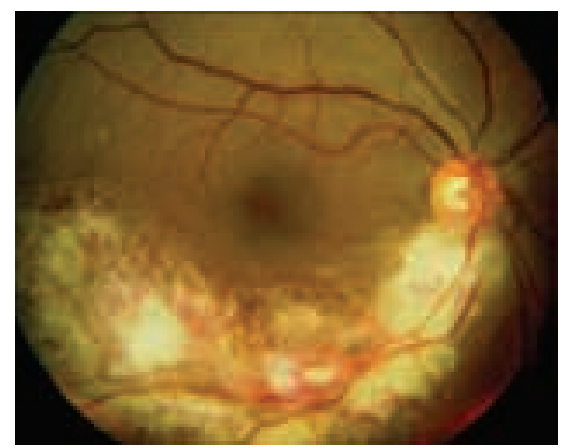

Figure 3: CMV Retinitis, right eye: Retinal hemorrbage, necrosis and edema3 month follow-up.

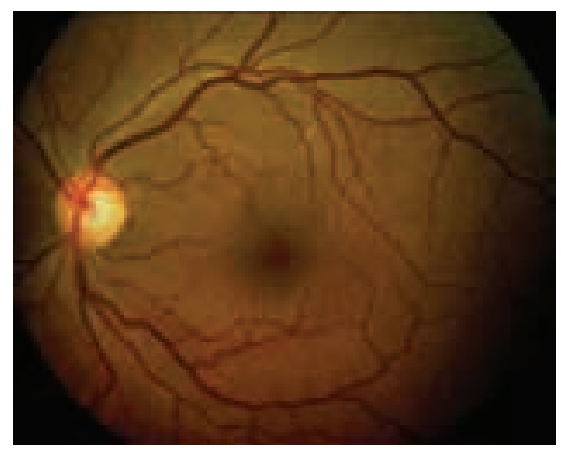

Figure 4: Resolving cotton-wool spot, left eye -3 month follow-up. at this first visit, no evidence of CMVR was noted. As a result of his elevated CMV DNA count, the patient was labeled at high risk for developing the condition.

At the one-month follow-up, a slight improvement in CD4 count was noted (10.4 cells $/ \mu \mathrm{L})$. Visual acuities were stable at 20/20-, right eye and left eye. Dilated fundus examination revealed two cottonwool spots at the posterior pole of the left eye. The right eye appeared stable from the previous visit, without signs of retinopathy or retinitis. The diagnoses and management plan remained consistent; the patient was instructed to return for follow-up one month later.

At the repeat dilated fundus exam, one month later, visual acuities were stable, however one cotton wool spot was detected at the posterior pole of the right eye, accompanied by a small hemorrhage. Two cotton wool spots were seen at the posterior pole of the left eye. The patient was then diagnosed with HIV retinopathy in both eyes, and deemed at high risk for CMVR. He was instructed to return to clinic no later than two weeks for follow-up.

The patient returned for followup one month later. CD4 count at that visit was stable at 10 cells $/ \mu \mathrm{L}$. The patient continued to report $100 \%$ compliance to the HAART treatment. Visual acuity of the right eye was found to be reduced to $20 / 40-$, left eye was relatively stable with an acuity of 20/20-.
Dilated fundus examination of the right eye revealed retinal hemorrhaging, necrosis, and edema along the inferior vascular arcade (Figure 3). Only one resolving cotton wool spot was seen in the left eye (Figure 4). The patient was diagnosed with CMVR of the right eye, HIV retinopathy of the left eye. The patient was immediately treated with Valgancyclovir $900 \mathrm{mg}$, orally, twice daily, for a period of two weeks. He was instructed to return to clinic four days later.

Subsequent follow-up examinations revealed improvement in CMVR of the right eye and HIV retinopathy of the left eye. After the initiation of anti-CMV therapy, the patient's CMV DNA count (real-time polymerase chain reaction) had been reduced to 252 copies $/ \mathrm{mL}$. The patient was discharged from the hospital approximately two weeks after he began treatment with oral valgancyclovir. Once the two-week induction dose of it was complete, the patient was prescribed a maintenance dose of oral valgancyclovir, $900 \mathrm{mg}$, daily, for an indefinite period of time.

At his most recent follow-up, approximately a month and a half after the patient's diagnosis with CMVR, the CD4 count remained low at 9 cells $/ \mu \mathrm{L}$. Visual acuity was measured to be $20 / 25$ in the right eye, 20/20 in the left eye. Fundus examination revealed a regressing retinitis of the right eye, and no signs of HIV retinopathy of the left eye. As a result, the 
TABLE 1.

Correlation between the patient's immune status and ophthalmic findings

\begin{tabular}{|c|c|c|c|c|c|c|}
\hline Visit & Date & $\begin{array}{c}\text { CD4+ } \\
\text { Count } \\
\text { (cells } / \mathrm{mL} \text { ) }\end{array}$ & $\begin{array}{l}\text { CMV viral } \\
\text { load } \\
\text { (copies/mL) }\end{array}$ & $\begin{array}{l}\text { Ophthalmic fundus } \\
\text { findings OD }\end{array}$ & $\begin{array}{l}\text { Ophthalmic fundus } \\
\text { findings OS }\end{array}$ & Diagnosis \\
\hline 1 & $10 / 2008$ & 9 & 2,733 & Clear & $\begin{array}{l}\text { Multiple cotton-wool } \\
\text { spots at the posterior } \\
\text { pole. No hemorrhages. } \\
\text { No exudation. }\end{array}$ & HIV Retinopathy OS \\
\hline 2 & $11 / 2008$ & 10.4 & Not tested & Clear & $\begin{array}{l}\text { Two cotton-wool spots } \\
\text { at the posterior pole. }\end{array}$ & HIV Retinopathy OS \\
\hline 3 & $12 / 2008$ & Not tested & Not tested & $\begin{array}{l}\text { One cotton-wool } \\
\text { spot and one small } \\
\text { hemorrhage at the } \\
\text { posterior pole. }\end{array}$ & $\begin{array}{l}\text { Two cotton-wool spots } \\
\text { at posterior pole. }\end{array}$ & HIV Retinopathy OU \\
\hline 4 & $01 / 2009$ & 10 & Not tested & $\begin{array}{c}\text { Retinal hemorrhaging, } \\
\text { necrosis and edema } \\
\text { along inferior vascular } \\
\text { arcade. }\end{array}$ & $\begin{array}{l}\text { One resolving cotton- } \\
\text { wool spot at the } \\
\text { posterior pole }\end{array}$ & $\begin{array}{c}\text { CMVR OD } \\
\text { HIV Retinopathy OS }\end{array}$ \\
\hline 5 & 01/2009* & 10 & 252 & $\begin{array}{l}\text { Retinal hemorrhage, } \\
\text { necrosis and edema } \\
\text { resolving. }\end{array}$ & Clear & $\begin{array}{l}\text { Resolving CMV } \\
\text { Retinitis OD }\end{array}$ \\
\hline 6 & $03 / 2009$ & 9 & $<200$ & $\begin{array}{l}\text { Retinal hemorrhage, } \\
\text { necrosis and edema } \\
\text { resolving. }\end{array}$ & Clear & $\begin{array}{l}\text { Resolving CMV } \\
\text { Retinitis OD }\end{array}$ \\
\hline
\end{tabular}

*Following initiation of anti-CMV therapy

patient was instructed to continue maintenance therapy with $900 \mathrm{mg}$ of oral valgancyclovir daily. The patient's HAART regimen was modified at that visit, with an additional protease inhibitor, Invirase ${ }^{\circledR}$ (Roche Pharmaceuticals, Nutley, New Jersey) added to the therapy in an attempt to further reconstitute the patient's immune status.

The patient was scheduled to be seen again, two weeks after his last visit to the Eye Clinic, but failed to keep his appointment.
(See Table 1 for a summary of the patient's immune status and ophthalmic disease throughout the course of his treatment.)

\section{Discussion}

HIV retinopathy is the most common ocular manifestation of AIDS, affecting between $40 \%$ and $60 \%$ of HIV-positive patients, typically with CD4 counts of less than 50 cells/ $\mu \mathrm{L} .{ }^{7}$ Clinically, this retinal microvasculopathy presents with cotton-wool spots and microaneurysms in the posterior pole.
Scattered dot and blot hemorrhages may be present, although cotton wool spots will rarely be associated with large amounts of hemorrhaging. ${ }^{7}$ These microvascular changes resemble those of nonproliferative diabetic retinopathy, and are thought to be the result of retinal ischemia caused by reduced erythrocyte flow in HIV-positive patients. ${ }^{6,8,9,10,11}$ It is suspected that this microvasculopathy can cause progressive thinning of the retinal nerve fiber layer ${ }^{12}$ and loss of axons in the optic nerve, ${ }^{13}$ leading to a variety of vision abnormalities, 
such as reduced colour vision, contrast sensitivity and visual field. ${ }^{14,15,16}$ Most patients with HIV retinopathy are asymptomatic, although occasionally a large cotton-wool spot located at the macula may cause a central scotoma. Rarely, this ischemic microvasculopathy reaches the foveal region, resulting in macular edema or serous maculopathy, which leaves the patient symptomatic for blurred vision or abrupt vision loss. ${ }^{7}$ In most cases, treatment for HIV retinopathy is not indicated. Focal laser photocoagulation would be indicated in the rare cases of macular edema. The presence of ischemic microvasculopathy is an important marker for patients with significantly compromised immune status who are at risk for developing more severe and vision-threatening ocular opportunistic infections. For patients with CD4 counts less than 50 cells $/ \mu \mathrm{L}$, it is recommended to perform a dilated fundus examination at 3-month intervals to routinely screen for CMVR. ${ }^{7}$ In the case reported above, due to the elevated cytomegalovirus load, the patient was deemed to be at very high risk for developing CMVR and was therefore dilated on a monthly basis.

Cytomegalovirus is a double stranded DNA herpes virus that causes a necrotizing retinitis in immune deficient hosts. ${ }^{17,18}$ CMVR is the most common ocular opportunistic infection associated with
AIDS, currently affecting approximately $9 \%$ of AIDS patients. ${ }^{7,19}$ Although the incidence of CMVR and the risk of associated retinal detachment has decreased since the advent of HAART. It remains the leading cause of ocular morbidity among patients with AIDS. ${ }^{7,20}$ CMVR occurs almost exclusively in patients with CD4 counts below 50 cells/ $\mu$ L. ${ }^{6,21}$ The average CD4 count at the time of diagnosis is 17 cells $/ \mu \mathrm{L}^{22}$

There are two clinical forms of CMVR. The fulminant form presents with confluent retinal necrosis and hemorrhaging in the posterior pole region. Patients with this form will typically be symptomatic for reduced visual acuity and visual field. The indolent form of CMVR presents as granular lesions in the peripheral retina, accompanied by frosted branch angiitis and little to no hemorrhaging. ${ }^{23}$ Patients with the above mentioned indolent form may commonly complain of floaters, or may be asymptomatic. In both cases, the retinal infection is "full-thickness" and begins peripherally and progresses centrifugally along the retinal vasculature. ${ }^{20}$ Although the patient in the above-mentioned case presented without symptoms, clinical signs of hemorrhaging and necrosis at the posterior pole indicated the fulminant form of this retinal infection. A low CD4 count makes inflammatory responses, such as vitritis, uncommon. ${ }^{24}$ Approximately $15 \%$ of patients with active
CMVR are asymptomatic, therefore it is recommended to perform dilated fundus exams at threemonth intervals when CD4 count is less than 50 cells $/ \mu \mathrm{L}^{25}$

Treatment of CMVR is not only based on the patient's immune status, but also takes into account the location of the active retinitis. ${ }^{7}$ Treatment typically includes initiating or modifying, a course of HAART in an effort to reconstitute the immune system. Since immune reconstitution can be delayed after the initiation of HAART, concomitant use of antiCMV agents is indicated in patients with posterior CMVR that is imminently vision threatening. ${ }^{7}$

The current standard for the treatment of CMV retinitis is systemic gancyclovir or its prodrug, valgancyclovir. Systemic gancyclovir is administered intravenously for a period of two to three weeks, at a dose of $5 \mathrm{mg} / \mathrm{kg}$, twice daily. This induction therapy is followed by maintenance with oral gancyclovir, at a dose of $30 \mathrm{mg}$ daily. ${ }^{7}$ Systemic valgancyclovir is considered to be equivalent to gancyclovir as initial therapy for CMVR, with an added advantage of being administered orally for both induction and maintenance therapy. ${ }^{6,26,27}$ The recommended oral dose for induction therapy is $900 \mathrm{mg}$, twice daily, for a period of two to three weeks. This is followed by oral maintenance therapy of $900 \mathrm{mg}$, daily. All above-mentioned doses assume normal renal function; as 
creatinine clearance reduces, the induction and maintenance doses are also reduced. Common secondary effects of the above-mentioned medications include blood dyscrasia (neutropenia, thrombocytopenia, anemia) and nephrotoxicity. ${ }^{28}$ Periodic monitoring of renal function and blood counts are recommended for all patients initiated on these therapies.

Other alterative treatments for CMVR include foscarnet, cidofovir and fomvirsen. Foscarnet is administered intravenously for both induction and maintenance therapy. It has been proven to have equal effectiveness as gancyclovir, only with more intolerable side effects. ${ }^{29}$ Secondary effects of foscarnet include seizures due to electrolyte imbalance, neutropenia and nephrotixicity. ${ }^{30,31}$ It has also been reported that $37 \%$ of patients on foscarnet develop resistance to the medication within a treatment period of nine months. ${ }^{32}$ Cidofovir administered intravenously, can be combined with oral gancyclovir to provide a synergistic effect that prolongs the patient's relapse-free intervals. ${ }^{33}$ Disadvantages of using cidofovir include secondary effects of proteinuria, peripheral neuropathy, ocular hypotony, and anterior uveitis. ${ }^{34,35}$ Ocular hypotony can be treated with a combination of topical ibopamine and dexamethasone. Anterior uveitis can be treated with topical corticosteroid therapy. ${ }^{36,37,38}$ As a second line of treatment, fomvirsen is adminis- tered intravitreally for both induction and maintenance therapy. Its use has been limited to cases of CMVR that are refractory to more conventional therapy; patients who are intolerant to the previously mentioned therapies; or in the presence of any contraindications to the alternative medications. The disadvantages of treating with fomvirsen lie within the secondary effects associated with intravitreal injections, they include: vitreous hemorrhage, retinal detachment and endophthalmitis.

The gancyclovir intravitreal implant may be used for induction and maintenance therapy and is most indicated in cases of maculathreatening CMVR. The implant is inserted through the pars plana and releases high levels of the drug directly into the vitreous humor for a period of approximately eight months. ${ }^{6}$ Advantages of the gancyclovir implant include local drug delivery at elevated concentrations providing the highest degree of viral suppression, longest relapse-free intervals, and lack of systemic toxicity. ${ }^{7,20}$ The disadvantages include potential complications of implant insertion, ${ }^{39,40}$ such as vitreous hemorrhage, endophthalmitis, retinal detachment, lack of protection against systemic CMV, or CMVR in the contralateral eye. ${ }^{7}$ In the case mentioned above, the infection appeared to be sparing the macula and, as a result, the risks of treating with a gancyclovir implant out-weighed

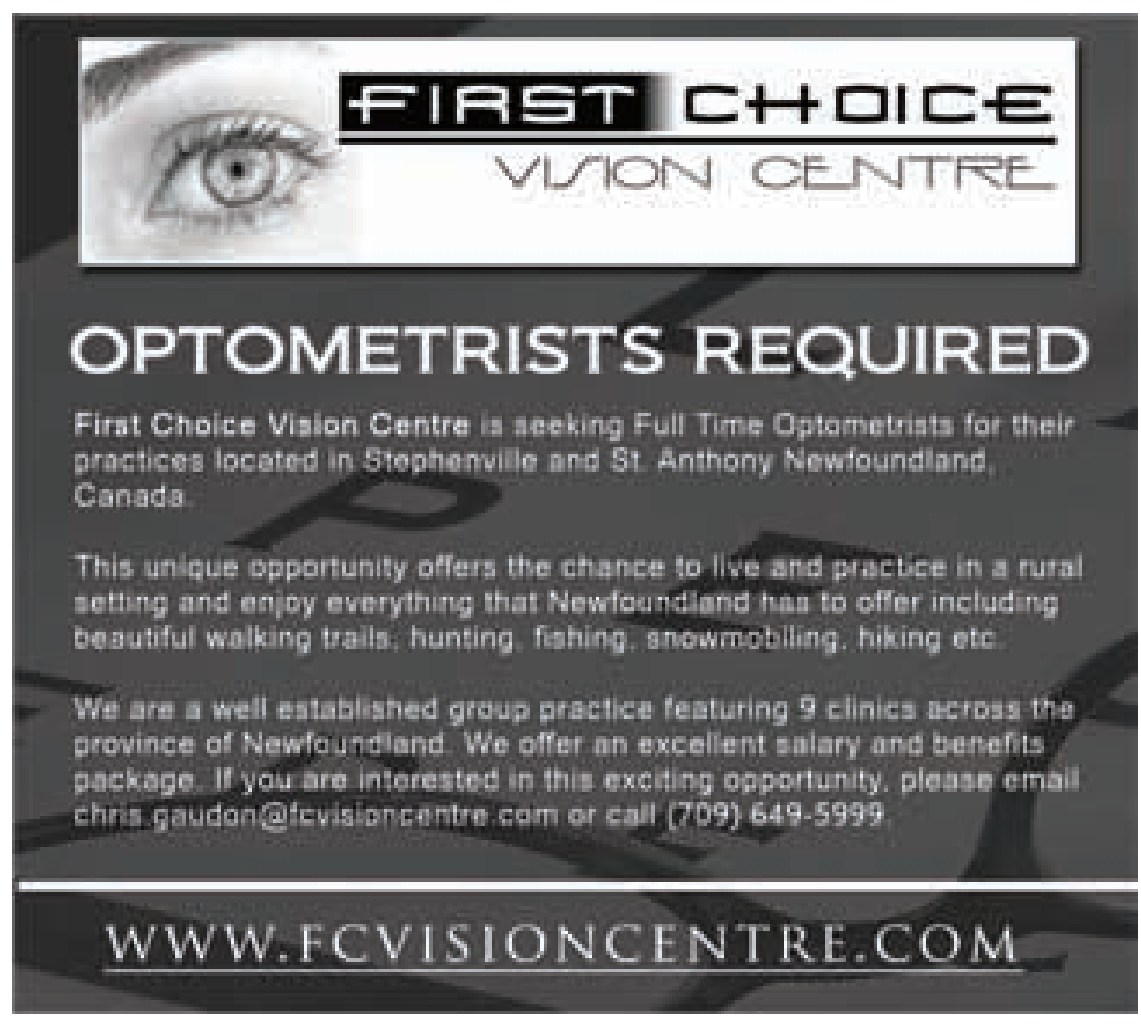


16. FreemanWR, van Natta ML, Jabs DA, et al. Vision function in HIV-infected individuals without retinitis: report of the Studies of Ocular Complications of AIDS Research Group. Am J Ophthalmol 2008;145:453-462.

17. Naraqi S. Cytomegaloviruses. In: Belshe RB, ed. Textbook of Human Virology. Littleton, MA: PSG Publishing Company, 1984:887-927.

18. Gallant JE, Moore RD, Richman DD, et al. Incidence and natural history of cytomegalovirus disease in patients with advanced human immunodeficiency virus disease treated with zidovudine. J Infect Dis 1992;166:1223-1227.

19. Mayo GL, Tolentino MJ. Cytomegalovirus retinitis. Focal Points 2007;25:1-16.

20. Goldberg DE, Smithen LM, Angelilli A, Freeman WR. HIV-associated retinopathy in the HAART era. Retina 2005;25:633-649.

21. Kuppermann BD, Petty JG, Richman $\mathrm{DD}$, et al. Correlation between CD4+ counts and prevalence of cytomegalovirus retinitis and human immunodeficiency virusrelated noninfectious retinal vasculopathy in patients with acquired immunodeficiency syndrome. Am J Ophthalmol 1993;115:575-82.

22. Pertel P, Hirschtick R, Phair J, et al. Risk of developing cytomegalovirus retinitis in persons infected with human immunodeficiency virus. J Acquir Immune Defic Syndr Hum Retrovirol 1992;5:1069-1074.

23. Raina J, Bainbridge JW, Shah SM. Decreased visual acuity in patients with cytomegalovirus retinitis and AIDS. Eye 2000;14:8-12.

24. Palestine AG, Rodrigues MM, Macher $\mathrm{AM}$, et al. Ophthalmic involvement in acquired immunodeficiency syndrome. Ophthalmology 1984;91:1092-1099.

25. Baldassano VF, Dunn JP, Feinberg J, et al. Cytomegalovirus retinitis and low CD4+ T-lymphocyte counts. N Engl J Med 1995;333:670.

26. Curran M, Noble S. Valgancyclovir. Drugs 2001;61:1145-1150.
27. Martin DF, Sierra-Madero J, Walmsley S, et al. A controlled trial of valgancyclovir as induction therapy for cytomegalovirus retinitis. $\mathrm{N}$ Engl J Med 2002;346:1119-1126.

28. Lalezari J, Lindley J, Walmsley S et al; Roche Valgancyclovir Study Group: A safety study of oral valgancyclovir maintenance treatment of cytomegalovirus retinitis. J Acquir Immune Defic Syndr 2002;30:392-400.

29. Studies of Ocular Complications of AIDS Research Group in collaboration with the AIDS Clinical Trials Group. Foscarnet-Gancyclovir cytomegalovirus retinitis trial 4: visual outcomes. Ophthalmology 1994;101:1250-1261.

30. Palestine AG, Polis MA, De Smet $\mathrm{MD}$, et al. A randomized controlled trial of foscarnet in the treatment of cytomegalovirus retinitis in patients with AIDS. Ann Intern Med 1991;115:665-673.

31. Lehoang Rd, Girard B, Robinet M, et al. Foscarnet in the treatment of cytomegalovirus retinitis in acquired immune deficiency syndrome. Ophthalmology 1989;96:865-873.

32. Jabs DA, Enger C, Forman M, Dunn JP. The Cytomegalovirus Retinitis and Viral Resistance Study Group: Incidence of foscarnet resistance and cidofovir resistance in patients treated for cytomegalovirus retinitis. Antimicrob Agents Chemother 1998;42:2240-2244.

33. Jacobson MA, Wilson S, Stanley H, et al. Phase I study of combination therapy with intravenous cidofovir and oral gancyclovir for cytomegalovirus retinitis in patients with AIDS. Clin Infect Dis 1999;28:528-533.

34. Ambati J, Wynne KB, Angerame MC, Robinson MR. Anterior uveitis associated with intravenous cidofovir use in patients with cytomegalovirus retinitis. Br J Ophthalmol 1999;83:11531158.

35. Cochereau I, Doan S, Diraison MC, et al. Uveitis in patients treated with intravenous cidofovir. Ocul Immunol Inflamm 1999;7:271-272.

36. Studies of Ocular Complications of AIDS Research Group in
Collaboration with the AIDS Clinical Trials Group. Parenteral cidofovir for cytomegalovirus retinitis in patients with AIDS: the HPMPC peripheral cytomegalovirus retinitis trial. A randomized, controlled trial. Ann Internal Med 1997;126:264-274.

37. Bainbridge JW, Raina J, Shah SM, et al. Ocular complications of intravenous cidofovir for cytomegalovirus retinitis in patients with AIDS. Eye 1999;13:353-356.

38. Studies of Ocular Complications of AIDS Research Group in Collaboration with the AIDS Clinical Trials Group. Longterm follow-up of patients with AIDS treated with parenteral cidofovir for cytomegalovirus retinitis: the HPMPC peripheral cytomegalovirus retinitis trial. AIDS 2000;14:1571-1581.

39. Guembel HO, Krieglsteiner $\mathrm{S}$, Rosenkranz C, et al. Complications after implantation of intraocular devices in patients with cytomegalovirus retinitis. Graefes Arch Clin Exp Ophthalmol 1999;237:824-829.

40. Lim JI, Wolitz RA, Dowling AH, et al. Visual and anatomic outcomes associated with posterior segment complications after gancyclovir implant procedures in patients with AIDS and cytomegalovirus retinitis. Am J Ophthalmol 1999;127:288-293.

41. Brosgart CL, Louis TA, Hillman DW et al. Terry Beirn Community Programs for Clinical Research on AIDS: A randomized, placebo-controlled trial of the safety and efficacy of oral gancyclovir for prophylaxis of cytomegalovirus disease in HIVinfected individuals. AIDS 1998;12:269277

42. Rose DN, Sacks HS. Cost-effectiveness of cytomegalovirus disease prevention in patients with AIDS: oral gancyclovir and CMV polymerase chain reaction testing. AIDS 1997;11:883-887.

43. Jabs DA, Enger C, Bartlett JG. Cytomegalovirus retinitis and acquired immunodeficiency syndrome. Arch Ophthalmol 1989;107:75-80. 